\title{
Leflunomide during pregnancy; a case report and review of the literature
}

\author{
Paul de Klaver ${ }^{1}$, Carolien Geesink ${ }^{1}$, Jasper Broen ${ }^{1}$, and Luc Derijks ${ }^{2}$ \\ ${ }^{1}$ Máxima Medical Center \\ ${ }^{2}$ Maxima Medical Center
}

August 16, 2021

\begin{abstract}
Leflunomide is a prodrug for teruflunomide and used for rheumatic diseases. Teriflunomide is considered to be teratogenic and should be avoided in pregnancy. We describe a case of teriflunomide exposure up to the third trimester of pregnancy. A healthy baby was delivered, despite substantial drug exposure. Multiple washout procedures were required to reduce teriflunomide concentrations below the safe target concentration $0.02 \mathrm{mg} / \mathrm{L}$.
\end{abstract}

\section{Hosted file}

LEF pregnancy_v3.docx available at https://authorea.com/users/430672/articles/534208leflunomide-during-pregnancy-a-case-report-and-review-of-the-literature

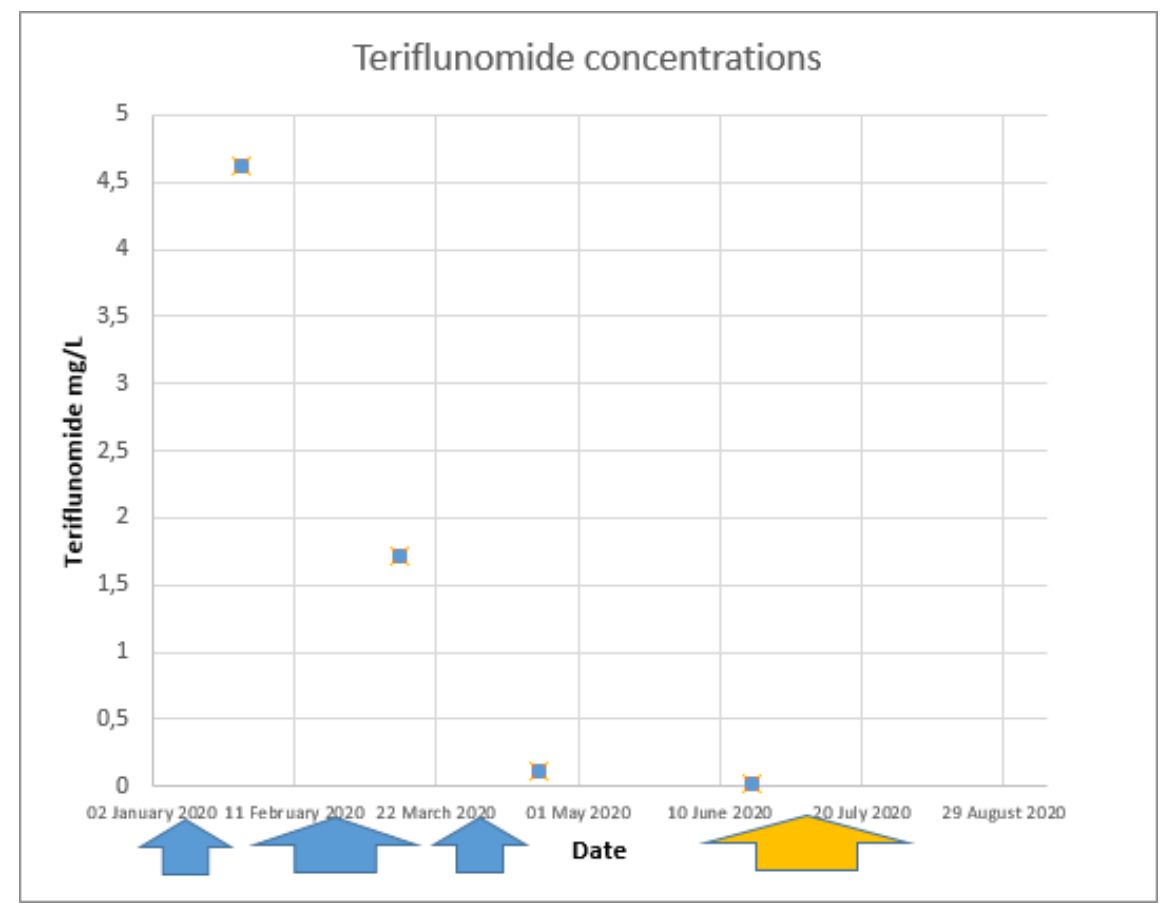

